\title{
A influência de Mancur Olson sobre a Teoria da Estabilidade Hegemônica de Robert Gilpin 1
}

The influence of Mancur Olson on the Hegemonic Stability Theory of Robert Gilpin

Juliany Helen das Graças Pinto²

\section{RESUMO}

Este artigo pretende compreender como a Teoria da Escolha Racional de Mancur Olson foi adaptada no campo das Relações Internacionais por Robert Gilpin. Para tanto, primeiro será analisada a bibliografia acerca do tema; depois, como a Teoria de Gilpin explicou o período do pós-guerra de liderança dos EUA no sistema internacional até os anos 1970. Logo, certificouse que a Teoria da Estabilidade Hegemônica de Gilpin foi inspirada na de Olson.

Palavras-chave: teoria política; escolha racional; teoria hegemônica.

\begin{abstract}
This article has the purpose to understand how the Rational Choice theory, by Mancur Olson, was adapted in the field of International relations by Robert Gilpin. To do so, first the written material about the topic will be analised; then, how the theory of Gilpin explained the period which followed world war II and the political leadership of the US until 1970. In conclusion, it was proved by this study that the Hegemonic Stability Theory was inspired in Olson
\end{abstract}

Key-words: political theory; rational choice; hegemonic theory.

O objetivo deste artigo é compreender como a Teoria da Escolha Racional de Mancur Olson ${ }^{3}$ foi adaptada no campo das Relações Internacionais na Teoria da

\footnotetext{
${ }^{1}$ Artigo recebido em 27 de agosto de 2013 e aprovado para publicação em 29 de setembro de 2013.

2 Estudante da graduação no curso de Ciências Sociais na Universidade Federal do Paraná e pesquisadora membro do Núcleo de Pesquisa em Relações Internacionais (NEPRI-UFPR) - contato: julianyhelen@ufpr.br. Curitiba, Brasil.

${ }^{3}$ Há inúmeros autores da ciência política que escrevem sobre a T. da Escolha Racional, porém o objetivo deste artigo não é fazer está exposição, mas sim mostrar a influência de uma interpretação específica da Ciência Política, a de Olson, sobre um autor específico das Relações Internacionais, o Gilpin. Para conhecer outras interpretações da Escolha Racional na ciência política, indico a leitura de BAERT, Patrick. Algumas limitações das explicações da escolha racional na Ciência Política e na Sociologia. 
Estabilidade Hegemônica de Robert Gilpin. Para tal análise, no primeiro momento é feita uma revisão bibliográfica acerca do tema; os problemas da operacionalização do conceito nas teorias tradicionais e, em seguida, é exposta a Teoria da Estabilidade Hegemônica de Gilpin no período de pós-guerra até os anos 1970.

A importância de discutir este assunto é a de levar em consideração a possibilidade de adaptar a análise da Ação Coletiva de Olson para examinar como um Estado pode desempenhar tarefas em um pequeno grupo, que seria o sistema internacional. À vista disso, levar em consideração um conceito usado na Teoria Política aplicada às Relações Internacionais de modo não desfavorável.

\section{Teoria da Escolha Racional - Ação Coletiva de Mancur Olson ${ }^{4}$}

A Teoria da Escolha Racional, de Mancur Olson, é aplicada a pequenos e, também, aos grandes grupos e pressupõe que nem sempre a presença de indivíduos com interesses semelhantes levará todos a agir da mesma forma para atingir um fim comum, pois os seres humanos são dotados de razão e agirão estrategicamente para melhor adequar os seus meios aos fins, resultando em menores prejuízos e maiores lucros individuais.

O trabalho de Olson gira em torno da ação de um ou vários indivíduos num determinado grupo para atingir um benefício público que é o fim que todos poderão usufruir.

O bem inclusivo é diferente do exclusivo. Este é o chamado "tudo ou nada", ou seja, só se alcança um determinado fim se todos os membros do grupo colaborarem; aquele é a denominação do ganho em que os membros que cooperam não perderão nada se um membro resolver não cooperar.

É necessário compreender a diferença da ação individual no grande e no pequeno grupo para depois maximizar a influência de um Estado na Ação Coletiva de um pequeno grupo, neste caso um grupo formado especificamente por Estados ${ }^{5}$.

\footnotetext{
${ }^{4}$ Foi um economista e cientista social norte-americano.

${ }^{5} \mathrm{Na}$ Teoria da Estabilidade Hegemônica de Robert Gilpin. 
No maior grupo, o membro analisará a relação custo-benefício, ou bem coletivo, onde mesmo aquele que não colaborou poderá usufruir do resultado da ação. Por exemplo, o indivíduo A, que pertence ao grupo de contribuintes do Brasil e sonega imposto e B paga todas as taxas impostas, mas A poderá usufruir das benfeitorias feitas pelo dinheiro arrecadado de B. Um dos benefícios feitos com o dinheiro arrecadado é a manutenção de estradas e, apesar de o indivíduo A não contribuir poderá, ainda assim, usá-las sem maiores complicações. Portanto é um bem universalmente usufruído, em que A terá $0 \%$ de ônus e 100\% de lucro. Apesar de todos ganharem com uma cooperação integral, a não participação será mais vantajosa, pois independentemente dos outros membros do grupo cooperarem ou deixarem de cooperar a vantagem será aproveitada pelo indivíduo.

O participante do maior grupo tem a consciência de que a sua ação não influencia muito no resultado final. 0 exemplo utilizado por Olson é sobre a ação de um empresário numa reunião com muitas pessoas, em que ele será atingido da mesma forma que todos os outros pelos resultados da reunião:

\footnotetext{
...tanto se aplicar muito quanto pequeno estudo sobre o assunto em pauta. Assim, o participante típico pode não se dar trabalho de estudar tão cuidadosamente o assunto da reunião quanto estudaria se pudesse tomar as decisões sozinho (Olson, 1999, p. 65).
}

Se o empresário estudar ou não cuidadosamente a pauta, as decisões dessa reunião serão benefícios públicos tanto para os que estiverem presentes como para os que não estiverem. Quanto maior for o grupo maior será a ausência de contribuição do indivíduo.

Para mostrar a dificuldade operacional do conceito de Ação Coletiva em grandes grupos usaremos a Teoria de Classes de Karl Marx relida por Olson. Marx dividiu a classe em termos da posse de meios de produção, mostrando que os membros da classe capitalista têm os mesmos interesses e os membros da classe proletária também têm interesses em comum; partindo do pressuposto de que, se uma classe atingir seu objetivo todos os indivíduos compartilharão do benefício.

Em 018 de Brumário de Luís Bonaparte, Marx apresenta a forma de operacionalizar a classe. Há a classe em si e a classe para si. A primeira descreve a dimensão objetiva, onde a classe social não é um agente político consciente de seus interesses; e a 
segunda com uma dimensão subjetiva, ou seja, a consciência de si como classe, as classes estão presentes, direta ou indiretamente, na cena política buscando seus objetivos coletivos estrategicamente (Perissinotto, 2007).

O ator racional, para Olson, é o homem econômico que, quando almeja algo, sempre escolherá um meio com melhor custo-benefício, mais adequadamente lucrativo, para chegar aos fins ambicionados. Eis o homem que calcula o que lhe é rentável. Aqui não se configura apenas o "empresário", mas qualquer homem devidamente adequado. 0 ganho não precisa ser necessariamente econômico, pode ser de ascensão dentro da sociedade, ou de mudança de cargo numa empresa ou algo para sua própria sobrevivência.

Para Olson o problema deste último tipo de representação é a dificuldade de pensar a classe como um ator político coletivo:

A ação de classe marxista assume o mesmo caráter de qualquer outro esforço de um grupo grande e latente para atingir suas metas coletivas. Uma classe nos padrões marxistas consiste em um grupo de indivíduos com um interesse comum decorrente do fato de possuírem ou não propriedade produtiva ou capital. Como em qualquer grupo grande e latente, cada membro da classe achará essa ação vantajosa para si se todos os custos ou sacrifícios necessários para atingir a meta comum forem assumidos por outros que não ele. (Olson, 1999, p. 121)

Sendo assim, não se pode afirmar que o "grupo de advogados deseja" ou o "grupo de operários quer", pois não há uma Ação Coletiva se os indivíduos partirem da razão, ou seja, não agirão coletivamente, mas sim individualmente (Perissinotto, 2007). Portanto, "a ação de classe não ocorrerá se os indivíduos que constituem uma classe agirem racionalmente" (Olson, 1999, p. 120).

Já o menor grupo é aquele em que um ou mais membros decidem pagar os custos de atingir um determinado fim e, ao contrário do maior grupo, a ação do ator é percebida. 0 conceito de Ação Coletiva só não constitui um problema para Olson quando um membro do grupo decide arcar com todos os custos para atingir um determinado fim. Os meios para atingir o objetivo não é problema. Até mesmo ter "caronas"6 em seu grupo é viável, pois não causará nenhum impacto sobre o bem almejado. Por exemplo, numa dada situação o aluno W decide fazer sozinho todos os trabalhos que foram propostos pelo professor, mas que

\footnotetext{
6 Num grupo em que há um membro decidido a aguentar todos os custos de uma ação coletiva, ele também levará um "carona” ou vários "caronas" que são aqueles que usufruem do esforço desse membro. 
deveriam ser feitos em grupo. Os "caronas" dessa situação são os colegas de grupo de W que não farão nenhuma rejeição à decisão tomada pelo aluno preocupado com seus próprios benefícios.

O aluno W não se preocupa em carregar "caronas" ao seu lado para a obtenção de benefícios coletivos e não leva em consideração as consequências de sua ação. Com o tempo ele poderá ficar exausto por ter de fazer as tarefas de mais de uma pessoa além das suas próprias atividades e não vai mais conseguir desempenhar o papel que se propôs para atingir seu próprio benefício.

E é sobre esse tipo de ação coletiva que será discorrido a partir de agora.

\section{Adaptação da Teoria da Escolha Racional de Olson na Teoria de Robert Gilpin?}

A Teoria Racional é adaptada por Gilpin e aplicada a um caso específico das Relações Internacionais em que um membro do grupo de Estados existentes no período de pós-Segunda Guerra até os anos 1970 decidiu arcar com todos os custos para atingir um conjunto de bens, que é coletivo, mas que, antes, é individual, isto é, proporcionará bens públicos com o intuito de beneficiar-se. E o país que fez esta escolha racional e estratégica para alcançar o seu objetivo é os Estados Unidos da América.

Comecemos pela explicação do que se trata a Teoria da Estabilidade Hegemônica tratada por Gilpin, nas palavras de Keohane:

\section{A teoria sustenta que as estruturas hegemônicas de poder, dominadas por um único país, são mais conducentes ao desenvolvimento de regimes internacionais fortes, com regras relativamente precisas e bem respeitadas (...). (Keohane, 1980, p. 132 citado por GILPIN, 2002, p. 93).}

A influência e status da potência hegemônica fazem com que outros Estados aceitem as regras propostas. A Teoria prossegue afirmando que a ordem econômica liberal não poderia prosperar se não houvesse um poder hegemônico, só há uma potência hegemônica se houver uma economia liberal e vice-versa. Ao contrário o que há é um sistema imperial e a imposição de restrições tanto políticas como econômicas às potências menores. E uma economia de

\footnotetext{
7 É um estudioso de Economia Política Internacional.
} 
mercado aberto representa um bem coletivo ou público, como vimos na seção destinada à teoria de Olson, um bem coletivo ou público é aquele que todos podem usufruir.

Na Teoria da Estabilidade Hegemônica é possível falar em bens públicos? Sendo que eles podem ser privados e apenas ditos como públicos; há diversos críticos desta Teoria e alguns dizem que para ser um bem público há a necessidade de muitos beneficiários. Sendo assim, o regime monetário e comercial não seriam bens coletivos.

Além disso, há quem note que os atores internacionais podem obter esses bens para si, e o fazem mediante a barganha, a cooperação mútua e a punição dos que desrespeitam as regras. Assim, para certos autores, o modelo apropriado para a economia internacional é o do 'dilema do prisioneiro', o problema da ação coletiva em que nações cooperam e negociam individualmente para alcançar seus objetivos econômicos (Conybeare, 1985 citado por GILPIN, 2002, p. 107).

Gilpin contesta os críticos. No campo das Relações Internacionais até mesmo os Estados individuais podem beneficiar-se de bens públicos - por exemplo, o regime de comércio aberto e liberal com base na cláusula de Nação mais Favorecida; moeda internacional estável; e a provisão de segurança internacional. Essa situação aproxima-se muito do exemplo da página 3, em que todos podem se beneficiar ou não com os resultados da reunião de negócios.

O sistema econômico liberal não pode ser autossustentável. É necessário que haja ações em longo prazo da economia dominante. Mesmo que haja a existência de "caronas", que é previsível numa economia mundial aberta, a potência líder deve arcar com todos os custos para manter o sistema. 0 número de beneficiários era suficientemente pequeno no período pós-1945 para facilitar a cooperação e para permitir que eles obtenham por si mesmos os bens de que necessitam. Logo, os EUA quiseram arcar com os custos uma vez que as vantagens seriam primeiramente individuais (para eles próprios) e depois coletivas.

Os Estados Unidos tiveram dificuldades para se ajustarem às mudanças na localização global das indústrias e no preço da energia a partir dos anos 1960. Com o passar dos anos, o mercado provoca mudanças profundas na localização das atividades econômicas, resultando na dificuldade de distribuição internacional do poder econômico e industrial do núcleo para os Estados em ascensão. A potência começa a ter problemas em custear o sistema. 
Os EUA concordaram em pgar os custos adicionais de sustentar o sistema econômico e político internacional, mas o que se pode perceber no período pós-Segunda Guerra Mundial até meados dos anos 1970 é que o pequeno grupo de países que os EUA estavam mantendo economicamente e politicamente teve um aumento expressivo. É o que observamos nos dados contidos no gráfico a seguir:

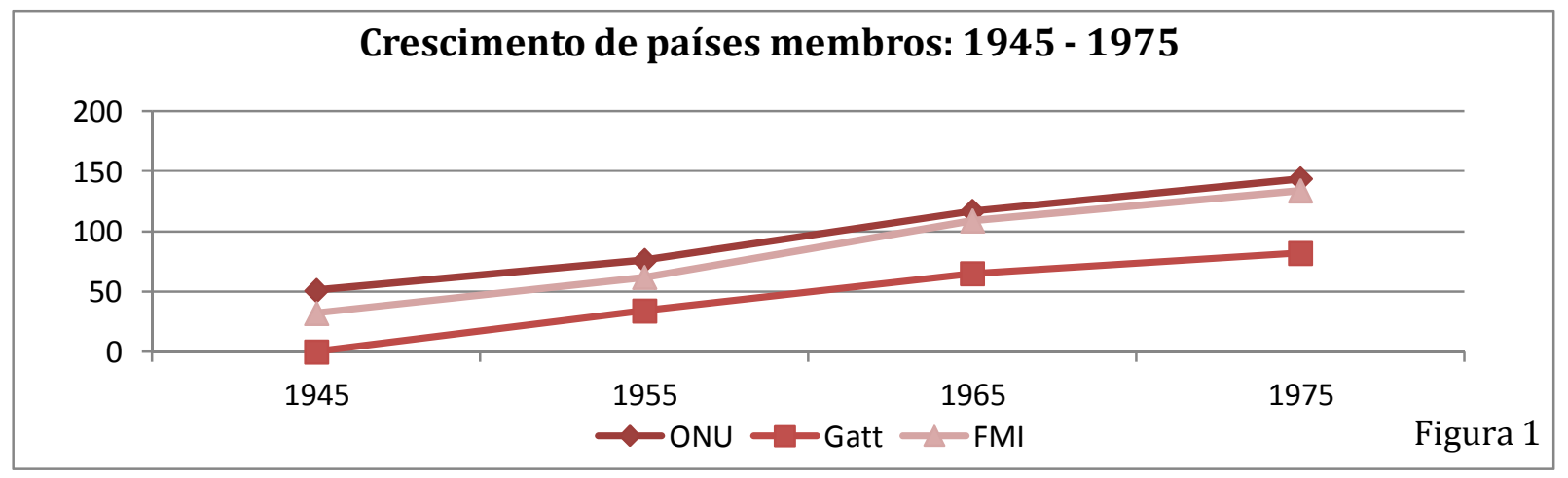

Na figura 1 podemos notar o aumento de países membros da Organização das Nações Unidas (ONU), do Acordo Geral de Tarifas e Comércio (Gatt) e do Fundo Monetário Internacional (FMI), ou seja, os países filiados a estas Organizações tiveram um grande acréscimo desde os anos de 1945.

O gráfico mostra o salto de membros de dez em dez anos, indicando que, por exemplo, a quantidade de membership do Gatt em 1945 era de zero e em 1965 já estava acima de sessenta. Lembrando que o Gatt e o FMI foram instituídos pelos EUA e incorporaram princípios liberais. Ora, os incentivos seletivos servem para que o membro principal seja beneficiado, isto é, os EUA não estavam fazendo um "favor" para os países aliados, pois só tinham a ganhar com a redução de barreiras econômicas e comerciais.

\footnotetext{
Quase todos os chamados bens coletivos internacionais só existem com respeito a um grupo de atores. O Gatt e o Fundo Monetário Internacional são bens públicos só para os seus membros, mas uma guerra comercial e a instabilidade do sistema monetário prejudicariam a todos. (Gilpin, 2002, p. 108).
}

Conforme aumentou o número de Estados, consequentemente houve o aumento dos "caronas" e o poder se deslocou para o Japão e para os países menos desenvolvidos. 0 comércio e a cooperação monetária se tornaram de difícil operacionalização. 
Os Estados podem ter incentivos para cooperar, mas têm igualmente um incentivo para agir de forma dolosa, aumentando, assim, sua vantagem relativa.

A Teoria da Estabilidade Hegemônica de Gilpin comprova a tese de Olson. Numa situação de Ação Coletiva que envolva membros racionais o mais provável é a abstenção, e não a cooperação como algumas teorias tradicionais afirmam como, por exemplo, a de classes defendida por Marx.

\section{A modo de desfecho}

Com base na elaboração deste artigo pode-se perceber que o conceito de Gilpin encontra alicerce nos de Olson. Termos usados em grupos de indivíduos também podem ser operacionalizados nas Relações Internacionais como, por exemplo, o termo "carona", utilizado tanto no texto de Olson como no de Gilpin. Com isso, verifica-se que as Relações Internacionais não estão tão longe da Teoria Política.

\section{Referências Bibliográficas}

GILPIN, Robert. 1987. A economia política das relações internacionais. ed. Universidade de Brasília, 2002.

MARX, Karl. 1984. 018 Brumário de Luís Bonaparte. ed. Lisboa: Avante.

OLSON, Mancur. 1999. A lógica da ação coletiva. São Paulo: Edusp

PERISSINOTTO, R. M. 2007. O 18 Brumário e a análise de classe contemporânea. Lua Nova n.71 São Paulo. Disponível em: http://www.scielo.br/scielo.php?script=sci_arttext\&pid=S010264452007000200004\&lng=pt\&nrm=iso. Acesso em 09/02/2013.

Membros do FMI. Disponível em: http://www.imf.org/external/np/sec/memdir/memdate.htm. Acesso em: 11/02/2013.

Membros do GATT. Disponível em: http://www.wto.org/english/thewto_e/gattmem_e.htm. Acesso em 11/02/2013.

Membros da ONU. Disponível em: http://www.un.org/es/members/growth.shtml\#1970. Acesso em 11/02/2013. 